\title{
Prevalence, trend and contributing factors of geriatric syndromes among older Swedes: results from the Stockholm County Council Public Health Surveys
}

\author{
Yajun Liang $^{1 *}$, Christian Rausch ${ }^{1,2}$, Lucie Laflamme ${ }^{1}$ and Jette Möller ${ }^{1}$
}

\begin{abstract}
Background: Evidence is scarce on the trend in prevalence of geriatric syndromes (GS). This study assesses how GS prevalence changes over time in Swedish older community-dwellers by socio-demography, and attempts to highlight factors that may contribute to explain the trend.

Methods: Data from Stockholm County Council Public Health Surveys in 2006, 2010 and 2014 were used. Old adults, aged 65-84 years, with measurements on GS items were identified. Thus, a total of 17,560 participants were selected in 2006 ( $n=6295), 2010(n=6733)$ and $2014(n=4532)$. Data on socio-demographics, lifestyles and health status were collected through questionnaires. GS was defined as having at least one of the following: insomnia, urinary incontinence, severe hearing/vision problem, functional decline, fall and depressive disorder. Logistic regression was performed to assess the prevalence trend as well as the change in the associations of sociodemographic factors, health behaviors and chronic disease with GS.

Results: From 2006 to 2014, the prevalence of GS remained stable ( $P_{\text {trend }}=0.54$ ). However, among old adults born outside Nordic countries, it increased significantly from 73.0\% in 2006, 78.0\% in 2010 to $83.0 \%$ in 2014 ( $P_{\text {trend }}<0$. 001). Furthermore, the association with GS became stronger for born outside Nordic counties $\left(P_{\text {trend }}<0.001\right)$ and weaker for sedentary lifestyles $\left(P_{\text {trend }}=0.004\right)$, whereas the association did not change for other sociodemographic factors, health behaviors and chronic disease (all $P_{\text {trend }}>0.05$ ).

Conclusions: At population level, GS prevalence remained stable at a high level among Swedish old communitydwellers. There are noteworthy differences in GS trend between population groups, in particular to the detriment of older adults born outside Nordic countries.
\end{abstract}

Keywords: Foreign-born, Geriatric syndromes, Health inequality, Population study

\section{Background}

As population is aging, health conditions in older adults require increased attention. In that age group, it is not just the single diseases but the concomitant presence of multiple chronic conditions that are increasingly prevalent and lead to high cost of healthcare [1-3]. Geriatric syndromes (GS) are such concomitantly occurring conditions that include pressure ulcers, incontinence, falls,

\footnotetext{
* Correspondence: yajun.liang@ki.se

${ }^{1}$ Department of Public Health Sciences, Karolinska Institutet, Widerströmska, 17177 Stockholm, Sweden

Full list of author information is available at the end of the article
}

functional decline and delirium [4]. Increased number of GS is associated with greater risk of incident physical disability and lower life satisfaction at the individual level $[5,6]$.

There are various factors associated with GS including older age (generally $>65$ years), unhealthy lifestyles (e.g., alcohol use disorder), functional impairment (e.g., impaired mobility or cognition), prior history of falls, diseases (e.g., multiple comorbidity) and use of medications (e.g., psychoactive medication use) [7-11]. Furthermore, socioeconomic positions (e.g., country of birth, education, occupation, income and wealth) over life course are

(c) The Author(s). 2018 Open Access This article is distributed under the terms of the Creative Commons Attribution 4.0 International License (http://creativecommons.org/licenses/by/4.0/) which permits unrestricted use, distribution, and reproduction in any medium, provided you give appropriate credit to the original author(s) and the source, provide a link to the Creative Commons license, and indicate if changes were made. The Creative Commons Public Domain Dedication waiver (http://creativecommons.org/publicdomain/zero/1.0/) applies to the data made available in this article, unless otherwise stated. 
associated with psychological, physical and cognitive functioning as well as mortality in old age [12-16]. Thus, GS items vary among different sociodemographic groups. For instance, urinary incontinence, falls, functional decline and depression occur more frequently in elderly women than in men [17-19]. People living alone or living in a rental accommodation or assisted living have higher risk of fall injury [17]. The changes in the contributors of GS and their impact on GS over time will contribute to the time trend in GS prevalence. Therefore, examining the trend in the associations between these contributors and GS will aid us to explain the time trends.

However, there is very few evidence on the prevalence trend of GS, especially on the possible contributors of the trend. In this study, we seek to fill in the knowledge gap by first assessing the trend of GS prevalence among old community-dwelling adults and in sub-groups depending on socio-demography, and then examining the changes in associations between possible contributors and GS over time.

\section{Methods}

\section{Study design and population}

This study was based the cross-sectional waves of Stockholm County Council Public Health Surveys (SCCPHS), which were undertaken for the purpose of health and risk factor surveillance as well as for policy formulation, planning and evaluation [20]. To date, four waves of SCCPHS have been completed in 2002, 2006, 2010 and 2014, respectively. In this study, we excluded the wave of 2002 due to a lot of missing information on GS. Therefore, three cross-sectional waves in 2006, 2010 and 2014 were included for assessing the prevalence trend.

For each cross-sectional survey, study sample was selected from the population of Stockholm County based on Swedish Total Population Register using an area-stratified randomization strategy. The eligible population of SCCPHS was those adults aged 18-84 years in 2006 and aged $\geq 18$ years in 2010 and 2014. There are 39 municipalities and urban districts in Stockholm County, and approximately 1300 individuals were sampled from each municipality. Therefore, a total of 50,000 individuals were selected at each survey. For the purpose of this study, we limited the analyses to old adults aged 65-84 years old and excluded the survey in 2002 due to incomplete information on GS. The number of participants (response rate, \%) were $6713(74.5 \%)$ in 2006, 7153 (74.1\%) in 2010, and 4726 (60.1\%) in 2014. After excluding participants with missing information on GS items, a total number of 17,560 old adults were included in the analyses with 6295 old adults in 2006, 6733 in 2010, and 4532 in 2014.
The particular research questions for this study were approved by the Stockholm Regional Ethical Review Board (Dnr 2011/344-31/5, 2013/466-32, 4-1540/2016 and 2016/1932-31/5). For each wave, all participants gave their informed consents by filling in the questionnaire and sending it back.

\section{Data collection and definitions}

Data were collected through postal-based questionnaires for individuals aged 65 years and above [20]. To reduce the non-response rate among immigrants, the questionnaire was translated into six languages (i.e., Arabic, Finnish, Turkish, Farsi, English and Spanish). In case there were persons, who originated from countries where these six languages are official languages and who did not respond to the translated postal questionnaire, a telephone interview in their mother tongue was performed [21]. Similar protocols were used for all three surveys. The self-reported questionnaires comprise about 100 questions covering health parameters including information on socio-demographic factors (such as age, sex, civil status, education, country of origin, living condition and financial status), health behaviors (such as smoking, alcohol intake, physical activity, sedentary lifestyle and nutrition), chronic conditions (such as obesity, hypertension, diabetes, cardiovascular diseases, chronic obstructive pulmonary disease [COPD], hearing impairment, vision problem, functional decline, insomnia, and urinary incontinence) [22].

Based on the previous literature [4, 23], GS was defined as having at least one of the following conditions: insomnia (i.e., having light to heavy sleeping problems), urinary incontinence (i.e., having light to heavy urine leakage), severe hearing problems (i.e., having difficulties in a conversation even with an aid), functional decline (i.e., unable to walk or run $100 \mathrm{~m}$ or use stairs), fall (i.e., had at least one injurious fall in the last six months), severe vision problems (i.e., cannot read or distinguish text in a newspaper even with glasses) and depressive symptom (i.e., score of general health questionnaire > 8) [24]. To assess the change of overall burden of GS at population level, both the GS (i.e., having any of the seven above conditions) and the specific GS were included as the variables of interest in the analyses.

Country of origin was grouped into Sweden, other Nordic countries and outside Nordic countries. Furthermore, a group of covariates including socio-demographic factors, health risk behaviors and health conditions were included in the analyses. Civil status was grouped into married, unmarried, divorced and widowed. Education was divided into three groups according to the highest attained level: primary school ( $\leq 9$ years of education), upper secondary school (10-12 years of education) and university education ( $\geq 12$ years of education). Type of 
housing included own, rent and other. Financial stress was defined as having financial hardship in general (e.g., managing the running costs for food, rent, bills, etc.) or in health (e.g., buying medications, going to the dentist or hospital).

Sedentary lifestyles was based on question regarding daily activities and defined as sitting the majority of the time. Current smoking was defined as self-reported of daily smoking currently. Alcohol drinking and nutrition were measured with reference to the last year. For instance, alcohol binge drinking was defined as drinking at least one bottle of wine (or corresponding amount) at least once per week. Unfavorable nutrition was defined as eating greens or fruits less than two times per month. Chronic disease was defined as having at least one of the following conditions including obesity (defined as having a body mass index $\geq 30 \mathrm{~kg} / \mathrm{m}^{2}$ ) and the self-reported physician diagnosis of hypertension, diabetes, heart diseases and COPD.

\section{Statistical analysis}

To describe the characteristics of participants across surveys, linear and logistic regression were performed. To assess the trends in prevalence in GS (i.e., having any of the seven GS items) and in specific GS, binary logistic regression was used with survey time as an independent variable after adjusting for socio-demographic factors, health behaviors and chronic disease. To assess the GS trend in different socio-demographic groups, stratified analyses were performed by age, sex, country of origin and education.

To examine the contributing factors of the trend, binary logistic regression models were used in two steps. First, we assessed the cross-sectional associations between potential contributors (socio-demographic factors, health behaviors and chronic disease) and GS within each survey. Second, we examined the trend in the strength of associations between these factors and GS across surveys, in which an interaction term between year of assessment and individual factors was included into the model together with covariates taking into account the differences in these factors across the three surveys.

Furthermore, the number (\%) of participants with missing information was $4(0.02 \%)$ for civil status, 2153 (12.3\%) for education, $150(0.8 \%)$ for type of accommodation, 498 (2.8\%) for financial stress, 560 (3.2\%) for sedentary lifestyle, 2337 (13.3\%) for alcohol drinking, 2163 (12.3\%) for smoking, 1011 (5.8\%) for nutrition and 383 (2.2\%) for chronic disease. When these factors were considered as covariates in subsequent analyses, a dummy variable for each of these factors was created to represent those with the missing value. Furthermore, sensitivity analysis with multiple imputation on these missing data was performed to test the robustness of the results.
IBM SPSS Statistics 25 for Windows (IBM SPSS Inc., Chicago, Illinois, USA) was used for all analyses.

\section{Results}

Table 1 shows the characteristics of participants in three surveys. The mean age slightly increased $(P<0.001)$ and the proportion of women varied over time $(P=0.011)$. Across the three surveys participants were more likely to be unmarried, highly educated, current smoking, have unfavorable nutrition and chronic disease, whereas less likely to be widowed, born outside Nordic countries, rent accommodation and have financial stress (all $P<0.01$ ). Compare to that in 2006, sedentary lifestyles became less prevalent in 2010 and more prevalent in 2014 $(P<0.001)$. There was no trend in alcohol binge drinking $(P=0.306)$ over time (Table 1).

Figure 1, Additional file 1: Table S1 and Table 2 show the trend in prevalence of GS and the trend stratified by age, sex, country of origin, education and specific GS. In all participants, the prevalence of GS did not change significantly over time in the crude model $\left(P_{\text {trend }}=0.540\right)$. After adjusting for socio-demographic factors, the prevalence slightly increased from 2006 to $2014\left(P_{\text {trend }}=0.042\right)$.

Notably, the prevalence of GS increased dramatically from 2006 to 2014 in the old adults born outside Nordic coutries ( $P_{\text {trend }}<0.01$ for all models), whereas no change was found in Swedish-born and those born in other Nordic countries. After stratification by level of education, the prevalence of GS increased over time among those with highest educational level of university education $\left(P_{\text {trend }}<0.001\right)$ or upper secondary school $\left(P_{\text {trend }}<\right.$ 0.001). Among those with highest educational level of secondary school, GS prevalence increased over time after adjusting for socio-demographic factors $\left(P_{\text {trend }}=\right.$ 0.011 ) but no significant change was observed after further adjusting for health behaviors and chronic disease (Fig. 1 and Table 2).

Among the seven specific GS, insomnia was the most common one, followed by urinary incontinence, severe hearing problem, functional decline, fall, severe vision problem and depressive disorder. After adjusting for covariates, the prevalence increased significantly over time for insomnia and fall (both $P_{\text {trend }}<0.001$ ), whereas decreased significantly for severe hearing problem, functional decline and severe vision problem (all $P_{\text {trend }}<0.001$ ). However, the prevalence did not change for urinary incontinence and depressive disorder (Fig. 1 and Table 2).

Furthermore, we assessed the trend in specific GS after stratification by country of origin. The results showed that among those born in Sweden, the prevalence increased over time for insomnia and fall (both $P_{\text {trend }}<$ 0.001), decreased for severe hearing problem, functional decline and severe vision problem (all $P_{\text {trend }}<0.001$ ), and remained stable for other items; among those born 
Table 1 Characteristics of participants in the surveys in 2006, 2010 and 2014

\begin{tabular}{|c|c|c|c|c|}
\hline Characteristics $^{a}$ & $2006(n=6295)$ & $2010(n=6733)$ & $2014(n=4532)$ & $P$ \\
\hline \multicolumn{5}{|l|}{ Socio-demography } \\
\hline Age (years) & $72.9(5.7)$ & $72.2(5.6)$ & $73.2(4.8)$ & $<0.001$ \\
\hline Women & $3452(54.8)$ & $3532(52.5)$ & $2479(54.7)$ & 0.011 \\
\hline \multicolumn{5}{|l|}{ Civil status } \\
\hline Married & $3542(56.3)$ & 3966 (58.9) & 2709 (59.8) & \multirow[t]{4}{*}{$<0.001$} \\
\hline Unmarried & $419(6.7)$ & $503(7.5)$ & $372(8.2)$ & \\
\hline Divorced & $1120(17.8)$ & $1281(19.0)$ & $816(18.0)$ & \\
\hline Widowed & $1214(19.3)$ & $983(14.6)$ & $631(13.9)$ & \\
\hline \multicolumn{5}{|l|}{ Country of origin } \\
\hline Sweden & $5194(82.5)$ & $5624(83.5)$ & 3861 (85.2) & \multirow[t]{3}{*}{0.004} \\
\hline Other Nordic countries & $523(8.3)$ & $501(7.4)$ & $312(6.9)$ & \\
\hline Outside Nordic countries & $578(9.2)$ & $608(9.0)$ & $359(7.9)$ & \\
\hline \multicolumn{5}{|l|}{ Education } \\
\hline University education & $1276(29.8)$ & $2123(32.0)$ & $1708(38.0)$ & \multirow[t]{3}{*}{$<0.001$} \\
\hline Upper secondary school & $1758(41.1)$ & $2714(40.9)$ & $1809(40.3)$ & \\
\hline Primary school & $1247(29.1)$ & $1796(27.1)$ & $976(21.7)$ & \\
\hline \multicolumn{5}{|l|}{ Type of accommodation } \\
\hline Own & $4302(68.7)$ & $4966(74.3)$ & $3512(78.7)$ & \multirow[t]{3}{*}{$<0.001$} \\
\hline Rent & $1757(28.0)$ & $1555(23.3)$ & $873(19.6)$ & \\
\hline Other & $205(3.3)$ & $160(2.4)$ & $80(1.8)$ & \\
\hline Financial stress & $745(12.0)$ & $609(9.5)$ & $361(8.2)$ & $<0.001$ \\
\hline \multicolumn{5}{|l|}{ Health behavior } \\
\hline Sedentary lifestyle & $840(13.7)$ & $765(11.7)$ & 647 (14.9) & $<0.001$ \\
\hline Alcohol binge drinking & $491(9.1)$ & 509 (8.6) & $321(8.2)$ & 0.306 \\
\hline Current smoking & $991(15.8)$ & $911(13.8)$ & $518(20.3)$ & $<0.001$ \\
\hline Unfavorable nutrition & $419(6.8)$ & $585(9.5)$ & $421(10.1)$ & $<0.001$ \\
\hline Chronic disease & $3671(60.0)$ & $4341(65.9)$ & 2967 (66.4) & $<0.001$ \\
\hline
\end{tabular}

Values are mean (SD) for age and $\mathrm{n}(\%)$ for others

${ }^{a}$ When the factors with missing values were considered as covariates in subsequent analyses, a dummy variable was created

in other Nordic countries, the prevalence decreased for severe hearing problem $\left(P_{\text {trend }}=0.027\right)$, and severe vision problem $\left(P_{\text {trend }}=0.037\right)$ but remained stable for other items; among those born outside Nordic countries, the prevalence increased over time for insomnia $\left(P_{\text {trend }}<\right.$ $0.001)$ but decreased for functional decline $\left(P_{\text {trend }}=0.026\right)$, no trend was found for other items (Additional file 1: Table S2).

Table 3 shows the trend in cross-sectional associations between various factors and GS. Within each survey, after adjusting for other covariates, the odds ratios of GS were significantly higher in those aged 75-84 years old (vs. those aged 65-74 years), women (vs. men), widowed (vs. married), born outside Nordic countries (vs. Swedish-born), living in other type of accommodation (vs. own accommodation) and in those having financial stress, sedentary lifestyle, alcohol binge drinking, unfavorable nutrition and chronic disease. Compared to that in 2006, after adjusting for confounders, the association with GS became stronger in later years for born outside Nordic countries compared to Swedish-born $\left(P_{\text {trend }}<0.001\right)$, whereas the association became weaker for sedentary lifestyles $\left(P_{\text {trend }}=0.004\right)($ Table 3$)$.

The sensitivity analysis from data imputation of missing characteristics showed unchanged results except that the annual change of GS prevalence became smaller in the subgroups by education. Furthermore, no trend was found for GS prevalence among those with education of university and above (Additional file 1: Table S3).

\section{Discussion}

In this study we found that the prevalence of GS remained quite stable during 2006 to 2014 among older community-dwellers in Stockholm. However, the prevalence of GS increased in the old adults born outside Nordic countries compared to that of the Swedish-born 

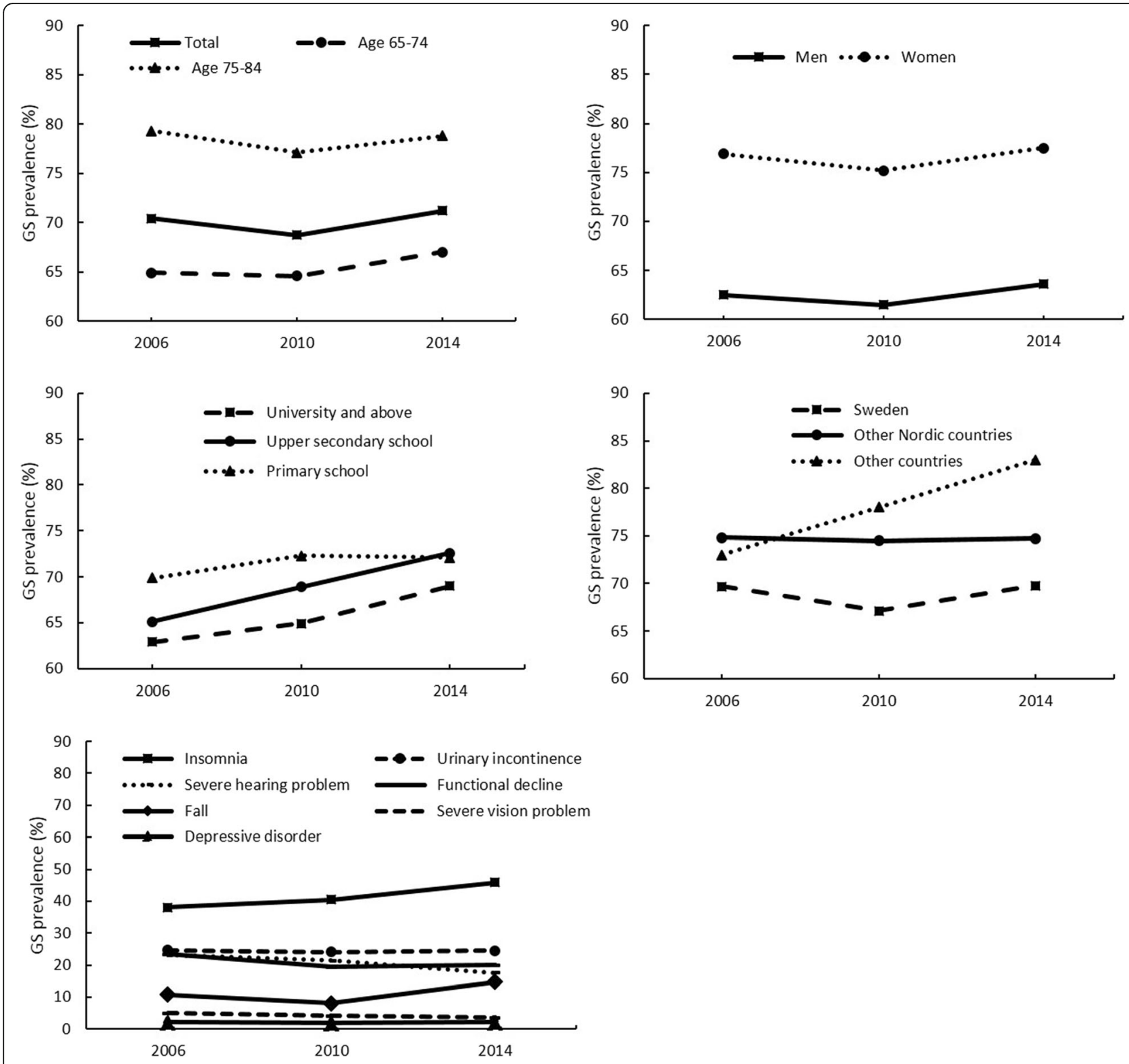

Fig. 1 Prevalence of geriatric syndromes (GS) in total participants and subgroups by age, sex, country of origin, education and specific GS

ones. This association became stronger over time independent of socio-demographic factors, health behaviors and chronic disease. Furthermore, there was a difference in trend among specific GS. The prevalence increased over time for insomnia and fall, decreased for severe hearing problem, functional decline and severe vision problem, whereas remained stable for urinary incontinence and depressive disorder.

We found that the prevalence of GS remained stable at a high level over time. There was very few evidence from previous studies on the trend of GS prevalence. One study in Swedish older-old adults (aged 77 years and older) assessed the trend in complex health problems defined as having severe problems in two or three domains (diseases/symptoms, mobility, and cognitive/ communication) [25]. They found that the prevalence decreased significantly from 1992 to 2002 but remained stable from 2002 to 2011 [25]. However, the comparison between our study and theirs was limited by the difference in study participants (e.g., our participants were younger) and variables of interest (i.e., we included different domains for GS definition). Nevertheless, we both found a stable prevalence over a same period. Regarding of the fastest growing population of old adults in Sweden, there will be an increasing number of people with GS even with a stable prevalence. These findings imply that increasing attention is needed from both clinical and public health perspective to reduce the health 
Table 2 Trend in prevalence of geriatric syndromes (GS) over time (2006-2014)

\begin{tabular}{|c|c|c|c|c|c|c|}
\hline & & $P_{\text {trend }}{ }^{a}$ & & & & \\
\hline & Annual change (\%) & Model 1 & Model 2 & Model 3 & Model 4 & Model 5 \\
\hline Total & 0.10 & 0.540 & 0.899 & 0.042 & 0.440 & 0.614 \\
\hline Age (years) & & & & & & \\
\hline $65-74$ & 0.26 & 0.094 & 0.716 & 0.127 & 0.486 & 0.892 \\
\hline $75-84$ & -0.06 & 0.551 & 0.997 & 0.073 & 0.950 & 0.453 \\
\hline Sex & & & & & & \\
\hline Men & 0.14 & 0.520 & 0.849 & 0.144 & 0.608 & 0.702 \\
\hline Women & 0.08 & 0.744 & 0.991 & 0.174 & 0.590 & 0.781 \\
\hline Country of origin & & & & & & \\
\hline Sweden & 0.01 & 0.896 & 0.693 & 0.260 & 0.131 & 0.385 \\
\hline Other Nordic countries & -0.01 & 0.965 & 0.452 & 0.810 & 0.576 & 0.200 \\
\hline Outside Nordic countries & 1.25 & $<0.001$ & 0.001 & $<0.001$ & $<0.001$ & 0.002 \\
\hline Education & & & & & & \\
\hline University and above & 0.76 & $<0.001$ & 0.473 & 0.234 & 0.800 & 0.532 \\
\hline Upper secondary school & 0.94 & $<0.001$ & 0.040 & 0.011 & 0.384 & 0.079 \\
\hline Primary school & 0.28 & 0.222 & 0.407 & 0.848 & 0.414 & 0.257 \\
\hline Specific GS & & & & & & \\
\hline Insomnia & 0.98 & $<0.001$ & $<0.001$ & $<0.001$ & $<0.001$ & $<0.001$ \\
\hline Urinary incontinence & -0.01 & 0.866 & 0.780 & 0.977 & 0.715 & 0.430 \\
\hline Severe hearing problem & -0.69 & $<0.001$ & $<0.001$ & $<0.001$ & $<0.001$ & $<0.001$ \\
\hline Functional decline & -0.42 & $<0.001$ & $<0.001$ & 0.559 & 0.001 & $<0.001$ \\
\hline Fall & 0.49 & $<0.001$ & $<0.001$ & $<0.001$ & 0.001 & $<0.001$ \\
\hline Severe vision problem & -0.18 & $<0.001$ & $<0.001$ & 0.055 & 0.001 & $<0.001$ \\
\hline Depressive disorder & 0.00 & 0.953 & 0.964 & 0.628 & 0.652 & 0.864 \\
\hline
\end{tabular}

${ }^{a}$ Model 1 was a crude model. Model 2 was adjusted for age and sex. Model 3 = Model 2 + other socio-demographic factors (e.g., civil status, country of origin, education, type of accommodation and financial stress). Model $4=$ Model 2 + health behaviors (e.g., unfavorable nutrition, sedentary lifestyle, alcohol binge drinking, and current smoking). Model $5=$ Model $2+$ chronic disease (e.g., cardiovascular diseases, COPD, obesity, hypertension and diabetes)

burden of Swedish aging population. Moreover, studying the change in numbers of GS might also be interesting to look at the development of GS. Regarding that our study is focusing on population level, future research at individual level is needed to look at the change in number of GS.

Notably, elderly people born outside Nordic countries had a higher prevalence of GS than native Swedes at each survey. This is consistent with the previous findings from the $\mathrm{H} 70$ gerontological and geriatric population studies in Gothenburg, which showed that compared with old native Swedes, 70-year-old migrants reported poorer health status (e.g., mental health, vision and urinary problems and general health) [26]. Furthermore, the prevalence of GS increased significantly from 2006 to later years in the old adults born outside Nordic countries which was not the case for the Swedish-born. One possible reason might be that old people born outside Nordic countries are socially and physically vulnerable due to their lower levels of social contacts, poor living conditions (e.g., housing conditions and economic status), less satisfaction with physical health status and lower levels of emotional functioning than the native Swedes [26, 27]. In addition, foreign-born people tend to use less in-hospital care compared to native Swedes, especially men, as regards symptoms, signs, and ill-defined conditions, injury and poisoning [28]. Further studies are needed to explore the underlying mechanism of increasing burden of GS among those elderly people born outside Nordic countries.

The prevalence of specific GS varied greatly from about $2 \%$ for depressive disorder to around $40 \%$ for insomnia. Although the prevalence of GS remained stable over time, different trends were found for specific GS. These findings raise the necessity of more emphasis on the prevention of those specific GS with high prevalence or increasing burden over time (e.g., insomnia and fall). At the same time, we have to keep in mind that GS are a mixture of multiple conditions that interact with each other with shared risk factors and shared pathophysiologic mechanisms, such as 
Table 3 The associations of socio-demography, health behaviors and chronic disease with geriatric syndromes

\begin{tabular}{|c|c|c|c|c|}
\hline \multirow[t]{2}{*}{ Characteristics } & \multicolumn{3}{|c|}{ Odds ratio $\left(95 \%\right.$ confidence interval) ${ }^{a}$} & \multirow[t]{2}{*}{$P_{\text {trend }}{ }^{a}$} \\
\hline & 2006 & 2010 & 2014 & \\
\hline \multicolumn{5}{|l|}{ Socio-demography } \\
\hline \multicolumn{5}{|l|}{ Age (years) } \\
\hline $65-69$ & Ref & Ref & Ref & \\
\hline $70-84$ & $1.49(1.23-1.80)$ & $1.62(1.43-1.84)$ & $1.68(1.44-1.95)$ & 0.566 \\
\hline \multicolumn{5}{|l|}{ Sex } \\
\hline Men & Ref & Ref & Ref & \\
\hline Women & $1.90(1.69-2.15)$ & $1.99(1.78-2.23)$ & $2.22(1.93-2.57)$ & 0.201 \\
\hline \multicolumn{5}{|l|}{ Civil status } \\
\hline Married & Ref & Ref & Ref & \\
\hline Unmarried & $1.12(0.88-1.43)$ & $1.06(0.86-1.31)$ & $1.02(0.79-1.32)$ & 0.665 \\
\hline Divorced & $1.10(0.94-1.30)$ & $1.09(0.94-1.26)$ & $0.87(0.72-1.06)$ & 0.187 \\
\hline Widowed & $1.21(1.02-1.44)$ & $1.19(0.99-1.42)$ & $1.27(1.01-1.59)$ & 0.590 \\
\hline \multicolumn{5}{|l|}{ Country of origin } \\
\hline Sweden & Ref & Ref & Ref & \\
\hline Other Nordic countries & $1.13(0.91-1.41)$ & $1.17(0.94-1.45)$ & $1.00(0.76-1.32)$ & 0.491 \\
\hline Outside Nordic countries & $0.92(0.75-1.14)$ & $1.50(1.21-1.86)$ & $1.85(1.37-2.50)$ & $<0.001$ \\
\hline \multicolumn{5}{|l|}{ Education } \\
\hline University education & Ref & Ref & Ref & \\
\hline Upper secondary school & $0.97(0.83-1.14)$ & $1.09(0.96-1.24)$ & $1.10(0.95-1.29)$ & 0.252 \\
\hline Primary school & $1.06(0.89-1.27)$ & $1.12(0.97-1.30)$ & $0.93(0.77-1.12)$ & 0.304 \\
\hline \multicolumn{5}{|l|}{ Type of housing } \\
\hline Own & Ref & Ref & Ref & \\
\hline Rent & $1.08(0.93-1.24)$ & $1.13(0.98-1.30)$ & $1.18(0.97-1.43)$ & 0.537 \\
\hline Other & $1.30(0.88-1.93)$ & $1.21(0.79-1.85)$ & $3.73(1.57-8.87)$ & 0.151 \\
\hline \multicolumn{5}{|l|}{ Financial stress } \\
\hline No & Ref & Ref & Ref & \\
\hline Yes & $2.14(1.71-2.68)$ & $2.24(1.76-2.86)$ & $2.91(2.04-4.14)$ & 0.130 \\
\hline \multicolumn{5}{|l|}{ Health behavior } \\
\hline \multicolumn{5}{|l|}{ Sedentary lifestyle } \\
\hline No & Ref & Ref & Ref & \\
\hline Yes & $4.03(3.10-5.23)$ & $2.34(1.91-2.87)$ & $2.34(1.86-2.95)$ & 0.004 \\
\hline \multicolumn{5}{|l|}{ Alcohol binge drinking } \\
\hline No & Ref & Ref & Ref & \\
\hline Yes & $1.33(1.07-1.67)$ & $1.60(1.28-1.99)$ & $1.45(1.09-1.93)$ & 0.895 \\
\hline \multicolumn{5}{|l|}{ Current smoking } \\
\hline No & Ref & Ref & Ref & \\
\hline Yes & $1.13(0.96-1.34)$ & $0.97(0.82-1.14)$ & $0.94(0.75-1.18)$ & 0.099 \\
\hline \multicolumn{5}{|l|}{ Unfavorable nutrition } \\
\hline No & Ref & Ref & Ref & \\
\hline Yes & $0.97(0.75-1.24)$ & $1.41(1.14-1.74)$ & $1.00(0.79-1.28)$ & 0.679 \\
\hline \multicolumn{5}{|l|}{ Chronic disease } \\
\hline No & Ref & Ref & Ref & \\
\hline Yes & $1.51(1.34-1.70)$ & $1.59(1.42-1.78)$ & $1.55(1.34-1.79)$ & 0.756 \\
\hline
\end{tabular}

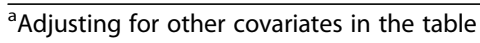


multisystem dysregulation, inflammation, sarcopenia and atherosclerosis $[4,29]$. The interactions between specific GS items may result in further functional impairments and higher disease burden [2]. Thus, the prevention on GS calls for a package intervention strategy through taking into account all of these GS items as a whole rather than just focusing on the ones of high and increasing prevalence.

In addition, we found that many risk factors were associated with GS including older age, being windowed, unfavorable accommodation, financial stress, sedentary lifestyle, alcohol binge drinking and chronic disease. This was consistent with previous studies on risk factors of GS [30]. Moreover, our study showed that the association between sedentary lifestyle and GS became weaker, whereas the association between other factors and GS remained stable over time. This finding suggest that sedentary lifestyle is becoming a less important contributor of GS, and further research is needed to explore other unknown determining factors to reduce GS among Stockholm community-dwellers.

One major strength of this study is the populationbased study design with large sample sizes. Second, the study protocol and data collection were consistent across all three surveys. However, this study also has limitations that needs to be acknowledged. First, although the participation rate $(60.1-74.5 \%)$ was relatively high compared with similar surveys [31], the non-respondents could still affect the study population structure and generalizability of our study findings to the whole population. Second, some migrant groups are under-represented in the SCCPHS, however, efforts have been made to overcome this problem, such as translating the questionnaire and offering telephone support [20, 21]. Third, GS were assessed based on self-reported information, which might underestimate the prevalence of some specific GS due to stigmatization or recall bias. Fourth, the association between various factors and GS were cross-sectional, which cannot indicate the causal relationship. Fifth, our study population only included those aged 65-84 years old and living in Stockholm, thus, caution is needed for the generalizability of our findings to other old population. Sixth, we were unable to assess the effect of length of residence due to the lack of data. Although the length of residence in Sweden is an important factor for health of adult immigrants [32], the question of length of stay is less likely to confound the association among older people that we study herein since most of the immigrants in our study originated from Europe, especially Nordic countries, with similar lifestyles before and after immigration.

\section{Conclusion}

The prevalence of GS remained stable at a high level over time in older community-dwellers living in Stockholm, however, with an increasing burden of GS among old adults born outside Nordic countries. Our findings imply that health inequalities due to country of origin persist and become larger during the studied period. Attention is needed to reduce these inequalities in older adults and to achieve healthy equity in ageing in Sweden, which is one of the countries that have the highest proportion of older people in the world together with high level of migration.

\section{Additional file}

Additional file 1: Table S1. The prevalence of geriatric syndromes in total participants and subgroups by age, sex, country of origin, education and specific items. Table S2. Trend in specific geriatric syndrome (GS) over time (2006-2014) in subgroups by country of origin. Table S3.

Trend in prevalence of geriatric syndromes (GS) over time (2006-2014) from data imputation of missing characteristics. (DOCX 26 kb)

\section{Abbreviations \\ COPD: Chronic obstructive pulmonary disease; GS: Geriatric syndromes; SCCPHS: Stockholm County Council Public Health Surveys}

\section{Acknowledgements \\ Not applicable.}

Funding

There was no funding to declare.

Availability of data and materials

The datasets used and/or analyzed during the current study are available from the corresponding author on reasonable request.

\section{Authors' contributions}

$Y L$ designed the study in collaboration with JM and LL. YL and CR assembled the database. YL analyzed the data and drafted the manuscript. All authors interpreted the data, revised the manuscript and approved the final version for submission.

\section{Ethics approval and consent to participate}

This study was approved by the Stockholm Regional Ethical Review Board. All participants gave their informed consents by filling in the questionnaire and sending it back.

Consent for publication

Not applicable.

\section{Competing interests}

The authors declare that they have no competing interests.

\section{Publisher's Note}

Springer Nature remains neutral with regard to jurisdictional claims in published maps and institutional affiliations.

\section{Author details}

${ }^{1}$ Department of Public Health Sciences, Karolinska Institutet, Widerströmska, 17177 Stockholm, Sweden. ${ }^{2}$ University Medical Center Groningen, Department of Health Sciences, Community and Occupational Medicine, University of Groningen, Groningen, The Netherlands.

Received: 7 June 2018 Accepted: 17 December 2018

Published online: 29 December 2018

References

1. Marengoni A, Angleman S, Melis R, Mangialasche F, Karp A, Garmen A, et al. Aging with multimorbidity: a systematic review of the literature. Ageing Res Rev. 2011;10:430-9. 
2. Prince MJ, Wu F, Guo Y, Gutierrez Robledo LM, O'Donnell M, Sullivan R, et al. The burden of disease in older people and implications for health policy and practice. Lancet. 2015;385:549-62.

3. Rizzuto D, Melis RJF, Angleman S, Qiu C, Marengoni A. Effect of chronic diseases and multimorbidity on survival and functioning in elderly adults. J Am Geriatr Soc. 2017:65:1056-60.

4. Inouye SK, Studenski S, Tinetti ME, Kuchel GA. Geriatric syndromes: clinical, research, and policy implications of a core geriatric concept. J Am Geriatr Soc. 2007;55:780-91.

5. Rosso AL, Eaton CB, Wallace R, Gold R, Stefanick ML, Ockene JK, et al. Geriatric syndromes and incident disability in older women: results from the women's health initiative observational study. J Am Geriatr Soc. 2013;61:371-9.

6. Yang DC, Lee JD, Huang CC, Shih HI, Chang CM. Association between multiple geriatric syndromes and life satisfaction in community-dwelling older adults: a nationwide study in Taiwan. Arch Gerontol Geriatr. 2015;60: 437-42.

7. Gunningberg L. Risk, prevalence and prevention of pressure ulcers in three Swedish healthcare settings. J Wound Care. 2004;13:286-90

8. Mecocci $P$, von SE, Cherubini $A$, Ercolani $S$, Mariani $E$, Senin $U$, et al. Cognitive impairment is the major risk factor for development of geriatric syndromes during hospitalization: results from the GIFA study. Dement Geriatr Cogn Disord. 2005;20:262-9.

9. Landi F, Cesari M, Russo A, Onder G, Lattanzio F, Bernabei R, Silvernet-HC Study Group. Potentially reversible risk factors and urinary incontinence in frail older people living in community. Age Ageing. 2003;32:194-9.

10. Gill T, Taylor AW, Pengelly A. A population-based survey of factors relating to the prevalence of falls in older people. Gerontology. 2005;51:340-5.

11. Spiers NA, Matthews RJ, Jagger C, Matthews FE, Boult C, Robinson TG, et al. Diseases and impairments as risk factors for onset of disability in the older population in England and Wales: findings from the Medical Research Council cognitive function and ageing study. J Gerontol A Biol Sci Med Sci. 2005:60:248-54.

12. Peters JL, Kubzansky LD, Ikeda A, Spiro A 3rd, Wright RO, Weisskopf MG, et al. Childhood and adult socioeconomic position, cumulative lead levels, and pessimism in later life. Am J Epidemiol. 2011;174:1345-53.

13. Fors $\mathrm{S}$, Modin B, Koupil I, Vågerö D. Socioeconomic inequalities in circulatory and all-cause mortality after retirement: the impact of mid-life income and old-age pension. Evidence from the Uppsala birth cohort study. J Epidemiol Community Health. 2012;66:e16.

14. Hurst L, Stafford M, Cooper R, Hardy R, Richards M, Kuh D. Lifetime socioeconomic inequalities in physical and cognitive aging. Am J Public Health. 2013;103:1641-8.

15. Ikram UZ, Mackenbach JP, Harding S, Rey G, Bhopal RS, Regidor E, et al. Allcause and cause-specific mortality of different migrant populations in Europe. Eur J Epidemiol. 2016;31:655-65.

16. Albin B, Hjelm K, Ekberg J, Elmståhl S. Higher mortality and different pattern of causes of death among foreign-born compared to native swedes 19701999. J Immigr Minor Health. 2006:8:101-13.

17. Helgadóttir B, Laflamme L, Monárrez-Espino J, Möller J. Medication and fall injury in the elderly population; do individual demographics, health status and lifestyle matter? BMC Geriatr. 2014;14:92

18. Leveille SG, Penninx BW, Melzer D, Izmirlian G, Guralnik JM. Sex differences in the prevalence of mobility disability in old age: the dynamics of incidence, recovery, and mortality. J Gerontol B Psychol Sci Soc Sci. 2000;55: S41-50

19. Fried LP, Tangen CM, Walston J, Newman AB, Hirsch C, Gottdiener J, et al. Cardiovascular Health Study Collaborative Research Group Frailty in older adults: evidence for a phenotype. J Gerontol A Biol Sci Med Sci. 2001;56: M146-56.

20. Svensson AC, Fredlund P, Laflamme L, Hallqvist J, Alfredsson L, Ekbom A, et al. Cohort profile: the Stockholm public health cohort. Int J Epidemiol. 2013; 42:1263-72.

21. Moradi T, Sidorchuk A, Hallqvist J. Translation of questionnaire increases the response rate in immigrants: filling the language gap or feeling of inclusion? Scand J Public Health. 2010;38:889-92.

22. Questionnaires. http://folkhalsoguiden.se/halsa-stockholm/. Accessed 24 Dec 2017.

23. Cigolle CT, Langa KM, Kabeto MU, Tian Z, Blaum CS. Geriatric conditions and disability: the health and retirement study. Ann Intern Med. 2007;147: $156-64$
24. Goldberg DP, Gater R, Sartorius N, Ustun TB, Piccinelli M, Gureje O, et al. The validity of two versions of the GHQ in the WHO study of mental illness in general health care. Psychol Med. 1997;27:191-7.

25. Meinow B, Kåreholt I, Thorslund M, Parker MG. Complex health problems among the oldest old in Sweden: increased prevalence rates between 1992 and 2002 and stable rates thereafter. Eur J Ageing. 2015;12:285-97.

26. Silveira E, Skoog I, Sundh V, Allebeck P, Steen B. Health and well-being among 70-year-old migrants living in Sweden--results from the $\mathrm{H} 70$ gerontological and geriatric population studies in Göteborg. Soc Psychiatry Psychiatr Epidemiol. 2002;37:13-22.

27. Hjern A. Migration and public health: health in Sweden: the National Public Health Report 2012. Chapter 13. Scand J Public Health. 2012;40:255-67.

28. Albin B, Hjelm K, Ekberg J, Elmståhl S. Utilization of in-hospital care among foreign-born compared to native swedes 1987-1999. Nurs Res Pract. 2012; 2012:713249.

29. Skalska A, Wizner B, Piotrowicz K, Klich-Rączka A, Klimek E, Mossakowska M, et al. The prevalence of falls and their relation to visual and hearing impairments among a nation-wide cohort of older poles. Exp Gerontol. 2013:48:140-6.

30. Tinetti ME, Inouye SK, Gill TM, Doucette JT. Shared risk factors for falls, incontinence, and functional dependence. Unifying the approach to geriatric syndromes. JAMA. 1995;273:1348-53.

31. Statistics Sweden. Technical Report: "Health on Equal Terms?" Public Health Survey 2010, National Sample Örebro: Statistics Sweden, 2010.

32. Johansson B, Helgesson M, Lundberg I, Nordquist T, Leijon O, Lindberg P, et al. Work and health among immigrants and native swedes 1990-2008: a register-based study on hospitalization for common potentially work-related disorders, disability pension and mortality. BMC Public Health. 2012;12:845.
Ready to submit your research? Choose BMC and benefit from:

- fast, convenient online submission

- thorough peer review by experienced researchers in your field

- rapid publication on acceptance

- support for research data, including large and complex data types

- gold Open Access which fosters wider collaboration and increased citations

- maximum visibility for your research: over $100 \mathrm{M}$ website views per year

At BMC, research is always in progress.

Learn more biomedcentral.com/submissions 